\title{
Worldwide Investing in Real Estate Using Interval-Valued Intuitionistic Fuzzy Sets
}

\author{
Irem Otay $^{1}$, Cengiz Kahraman ${ }^{2}$ \\ ${ }^{1}$ ITU Management Engineering Department 34367Macka-Istanbul, Turkey \\ ${ }^{2}$ ITU Industrial Engineering Department 34367Macka-Istanbul, Turkey \\ \{iremotay,kahramanc\}@itu.edu.tr
}

\begin{abstract}
Global real estate investments have been one of the popular investment areas since developments in transportation vehicles among countries, significant reduction in travelling costs, and suitable legal arrangements for purchasing real estates in a foreign country have made it attractive. This investment decision is composed of three stages: Selection of a country, selection of a city, and selection of a district for a real estate. Since the selection process includes uncertain and vague evaluations under multiple criteria, a fuzzy multicriteria evaluation method is needed. In this paper we use interval-valued intuitionistic fuzzy sets to model this multicriteria and multiexpert problem.
\end{abstract}

Keywords: MCDM, interval-valued intuitionistic, fuzzy, real estate, investment decision

\section{Introduction}

Investing in real estate includes the purchase, ownership, management, rental and/or resale of real estate for profit. Globalization causes a significant increase in cross-border and cross-continental movements of people. They can now travel faster and regularly visit what used to be very remote parts of the world. This human mobility has brought to mind the purchase of a house or an apartment in the countries often visited. Becoming a citizen of another country is now much easier relative to the past. In addition, retirees often image living in another country suitable to their budget and health conditions.

The decision making process related to real estate investments requires to evaluate the problem from different perspectives considering many factors from social to economic and from intangible to tangible. Therefore, the worldwide real estate investment making problem is a typical multicriteria decision making (MCDM) problem requiring careful assessment of alternatives and evaluating a wide variety of criteria such as Environment \& Climate, Geographical location, Spoken language and Development level to make an appropriate decision. This decision includes a variety of stages ranging from country selection to city selection and real estate district selection decisions. Every stage requires linguistic evaluations rather than exact numerical values because of uncertainties and subjectiveness in the evaluations of human beings.

The fuzzy set theory is an excellent tool to handle the uncertainty in case of insufficient data. Its principals are similar to human beings' thinking style. Ordinary fuzzy sets have recently been extended to hesitant fuzzy sets, intuitionistic fuzzy sets, type-2 fuzzy sets, nonstationary fuzzy sets, and fuzzy multisets (Rodriguez et al., 2012). The most used extensions among these are hesitant fuzzy sets and intuitionistic fuzzy sets. Hesitant Fuzzy Sets (HFS) were introduced by Torra (2010) as a new extension of fuzzy sets, motivated for the common difficulty that often appears when the membership degree of an element must be established. This difficulty is very usual in decision making when an expert might consider different degrees of membership of an element $x$ in the set A (Rodriguez et al., 2012).

An intuitionistic fuzzy set (IFS) has three functions to define it: the membership function, the nonmembership function and the hesitancy function. Atanassov and Gargov (1989) proposed interval-valued intuitionistic fuzzy sets theory (IVIFS), which is a generalization of both interval valued fuzzy sets and intuitionistic fuzzy sets. Their concept is characterized by a membership function and a non-membership function whose values are intervals rather than a real number. IVIFS is more powerful in dealing with vagueness and uncertainty than IFS (Broumi and Smarandache 2014).

In the literature, there are many MCDM methods for the selection among multiple alternatives such as analytic hierarchy process (AHP) (Saaty, 1980), Technique Ordered Preference by Similarity to the Ideal Solution (TOPSIS) (Hwang and Yoon, 1981), Multi-criteria optimization and compromise solution (VIKOR) (Opricovic and Tzeng, 2004), ELimination and Choice Expressing the Reality (ELECTRE) (Roy, 1991), Preference Ranking Organisation MeTHod for Enrichment Evaluations (PROMETHEE) (Brans, 1982) and Analytic Network Process (ANP) (Saaty, 2006). The extensions of these methods have been developed under fuzziness and already published in the literature. However, in this paper we focus on pairwise comparisons of criteria as in AHP method by using interval-valued intuitionistic fuzzy sets. Later, the evaluations of alternatives are based on interval-valued intuitionistic Simple Additive Weighting method utilizing aggregation operators. 
The originality of this paper comes from the evaluation of international real estate investment decision by constructing the problem as a multi-stage decision making problem. The proposed methodology consists of three stages which are country selection, city selection and real estate district selection. However, in this study, only real estate district selection decision in a predetermined city is realized by using interval-valued intuitionistic fuzzy sets. We used a new methodology based on intuitionistic fuzzy Simple Additive Weighting method and intuitionistic pairwise comparisons. The rest of the paper is organized as follows: Section 2 gives brief information about literature review on real estate investment decision. Section 3 presents the basics of intervalvalued intuitionistic fuzzy sets while Section 4 gives the steps of the fuzzy multicriteria method. Section 5 demonstrates the application of the methodology. In the last section, conclusion remarks and future research directions are included.

\section{Worldwide investing in real estate: literature re- view}

Investing in real estate is a popular problem area in the literature. Even we could not find any publication handling three stage investments making in real estate, there are many works focusing on the real estate selection problem. Thomas (2002) proposes a Brownfield Site Ranking Model for selecting sites for potential redevelopment. This process identifies 11 siting criteria derived from the review of general siting factors. These factors include commercial marketing guidelines, financial incentives, environmental regulatory compliance requirements, regional infrastructure, and local community acceptance. The considered main and subcriteria are as follows: Site Conditions: Environmental contamination, environmental problems, physical development constraints. Current Use Compatibility with Local Plans: Compliant, Not compliant. Compatibility with Surrounding Land Uses: Compatible, compatible with reservations, not compatible. Utility Infrastructure Capacity. Telecommunications Infrastructure. Transportation Infrastructure: Interstate access/rail/airport, highways, county roads, local streets.

Lin and Lin (2013) present a novel approach for evaluating real estate purchases in Taipei. The proposed approach focuses on encouraging purchases to achieve better housing performance and supporting homebuyers in housing comparison and selection decisions. The proposed approach compares the features of different houses by integrating the Fuzzy Geographic Information Systems (GIS) method with an Analytic Hierarchy Process (AHP). The comprehensive evaluation of uncertainty variable data includes 20 housing performance indicators selected from a review of existing models, and GIS. The weights of each category and indicator are calculated by employing AHP analysis.
Xue (2005) makes an analysis on the risk in real estate development using project risk management theory and setting real estate developer as main exploring object. In the study, the risk element weight is also determined. The paper also provides an idea for building a real estate development multi-layer fuzzy comprehensive evaluation model. The paper makes comparisons the purposed method with AHP method and highlights the advantages of the proposed method.

Taking the above references into account, we determine the following evaluation criteria for making a preference among real estate district alternatives: purchasing cost, expected increase in its value, neighborhood, closeness to hospitals, closeness to transportation vehicles, closeness to schools, and closeness to malls.

\section{Interval-valued intuitionistic fuzzy sets}

In the fuzzy set theory, the membership of an element to a fuzzy set is a single value between zero and one. However, the degree of non-membership of an element in a fuzzy set may not be equal to 1 minus the membership degree since there may be some hesitation degree. Therefore, a generalization of fuzzy sets was proposed by Atanassov (1986) as intuitionistic fuzzy sets (IFS) which incorporate the degree of hesitation, which is defined as 1 minus the sum of membership and nonmembership degrees.

Let $X \neq \emptyset$ be a given set. An intuitionistic fuzzy set in $\mathrm{X}$ is an object $\mathrm{A}$ given by

$$
\tilde{A}=\left\{\left\langle x, \mu_{\tilde{A}}(x), v_{\tilde{A}}(x)\right\rangle ; x \in X\right\},
$$

where $\mu_{\tilde{A}}: X \rightarrow[0,1]$ and $v_{\tilde{A}}: X \rightarrow[0,1]$ satisfy the condition for every $x \in X$.

$$
0 \leq \mu_{\tilde{A}}(x)+v_{\tilde{A}}(x) \leq 1,
$$

Hesitancy is equal to " $1-\left(\mu_{\tilde{A}}(x)+v_{\tilde{A}}(x)\right)$ ".

The definition of interval-valued intuitionistic fuzzy sets (IVIFS) is given as follows. Let $\mathrm{D} \subseteq[0,1]$ be the set of all closed subintervals of the interval and $\mathrm{X}$ be a universe of discourse. An interval-valued intuitionistic fuzzy set in $\tilde{A}$ over $\mathrm{X}$ is an object having the form

$$
\tilde{A}=\left\{<x, \tilde{\mu}_{A}(x), \tilde{v}_{A}(x)>\mid x \in X\right\},
$$

where

$\tilde{\mu}_{\tilde{A}} \rightarrow D \subseteq[0,1], \tilde{v}_{\tilde{A}}(x) \rightarrow D \subseteq[0,1]$ with the condition $0 \leq \sup \tilde{\mu}_{\tilde{A}}(x)+\sup \tilde{v}_{\tilde{A}}(x) \leq 1, \forall x \in X$.

The intervals $\tilde{\mu}_{\tilde{A}}(x)$ and $\tilde{v}_{\tilde{A}}(x)$ denote the membership function and the non-membership function of the element $\mathrm{x}$ to the set $A$, respectively. Thus, for each $\mathrm{x} \in \mathrm{X}$, $\tilde{\mu}_{\widetilde{\mathrm{A}}}(\mathrm{x})$ and $\widetilde{\mathrm{V}}_{\widetilde{\mathrm{A}}}(\mathrm{x})$ are closed intervals and their lower and upper end points are denoted by $\tilde{\mu}_{\widetilde{A L}}(\mathrm{x}), \tilde{\mu}_{\widetilde{\mathrm{AU}}}(\mathrm{x})$, $\tilde{v}_{\widetilde{A L}}(x)$, and $\tilde{v}_{\tilde{A} U}(x)$, respectively. Interval-valued intiutionistic fuzzy set $\tilde{A}$ is then expressed by $\tilde{A}=\left\{<x,\left[\tilde{\mu}_{\widetilde{\mathrm{AL}}}(\mathrm{x}), \tilde{\mu}_{\widetilde{\mathrm{AU}}}(\mathrm{x})\right],\left[\tilde{v}_{\widetilde{A L}}(x), \tilde{v}_{\tilde{A} U}(x)\right]>\mid x \in X\right\}$, where

$$
0 \leq \tilde{\mu}_{\widetilde{A U}}(\mathrm{x})+\tilde{v}_{\widetilde{A} U}(x) \leq 1, \tilde{\mu}_{\widetilde{A L}}(\mathrm{x}) \geq 0, \tilde{v}_{\widetilde{A L}}(x) \geq 0 .
$$


For each element $\mathrm{x}$, we can compute the unknown degree (hesitancy degree) of an interval-valued intuitionistic fuzzy interval of $x \in X$ in $\tilde{A}$ defined as follows:

$$
\begin{gathered}
\pi_{\tilde{A}(x)}=1-\tilde{\mu}_{\widetilde{\mathrm{A}}}(\mathrm{x})-\tilde{v}_{\widetilde{A}}(x) \\
=\left(\left[1-\tilde{\mu}_{\widetilde{\mathrm{AU}}}(\mathrm{x})-\tilde{v}_{\widetilde{A} U}(x)\right],\left[1-\tilde{\mu}_{\widetilde{A L}}(\mathrm{x})-\tilde{v}_{\widetilde{A L}}(x)\right]\right)
\end{gathered}
$$

For convenience,

$$
\begin{gathered}
\text { Let } \tilde{\mu}_{\widetilde{\mathrm{A}}}(\mathrm{x})=\left[\mu^{-}, \mu^{+}\right], \tilde{v}_{\tilde{A}}(x)=\left[v^{-}, v^{+}\right], \\
\text {so } \tilde{A}=\left(\left[\mu^{-}, \mu^{+}\right],\left[v^{-}, v^{+}\right]\right) .
\end{gathered}
$$

Some arithmetic operations with interval-valued intuitionistic fuzzy sets and $\lambda \geq 0$ are given in the following: Let

$\tilde{I}_{1}=\left(\left[\mu_{1}{ }^{-}, \mu_{1}{ }^{+}\right],\left[v_{1}{ }^{-}, v_{1}{ }^{+}\right]\right), \tilde{\mathrm{I}}_{2}=\left(\left[\mu_{2}{ }^{-}, \mu_{2}{ }^{+}\right],\left[\mathrm{v}_{2}{ }^{-}, \mathrm{v}_{2}{ }^{+}\right]\right)$ be two interval-valued intuitionistic fuzzy sets. Then, some of the arithmetic operations for these singleton sets are given in Eqs. (6)-(8):

\section{Addition:}

$$
\begin{aligned}
\tilde{I}_{1} \oplus \tilde{I}_{2}= & \left(\left[\mu_{1}^{-}+\mu_{2}^{-}-\mu_{1}^{-} \mu_{2}^{-}, \mu_{1}^{+}+\mu_{2}^{+}-\mu_{1}^{+} \mu_{2}^{+}\right]\right. \\
& \left.\cdot\left[v_{1}^{-} v_{2}^{-}, v_{1}^{+} v_{2}^{+}\right]\right)
\end{aligned}
$$

\section{Multiplication:}

$$
\begin{aligned}
\tilde{\mathrm{I}}_{1} \otimes \tilde{\mathrm{I}}_{2}= & \left(\left[\mu_{1}^{-} \mu_{2}^{-}, \mu_{1}^{+} \mu_{2}^{+}\right],\left[\mathrm{v}_{1}^{-}+\mathrm{v}_{2}^{-}-\mathrm{v}_{1}^{-} \mathrm{v}_{2}^{-},\right.\right. \\
& \left.\left.\mathrm{v}_{1}^{+}+\mathrm{v}_{2}^{+}-\mathrm{v}_{1}^{+} \mathrm{v}_{2}^{+}\right]\right)
\end{aligned}
$$

\section{Multiplication by a constant:}

$$
\begin{aligned}
\lambda \tilde{I}_{1}= & \left(\left[1-\left(1-\mu_{1}^{-}\right)^{\lambda}, 1-\left(1-\mu_{1}^{+}\right)^{\lambda}\right],\right. \\
& {\left.\left[\left(v_{1}^{-}\right)^{\lambda},\left(v_{1}^{+}\right)^{\lambda}\right]\right) }
\end{aligned}
$$

The necessary definitions used in the multiexpert and multicriteria fuzzy methodology are stated in the following (Xu, 2010; Chen et al., 2011):

Definition 1: Let $\tilde{\alpha}_{j}=\left(\left[a_{j}, b_{j}\right],\left[c_{j}, d_{j}\right]\right)(j=1,2, \ldots, n)$ be a collection of interval-valued intuitionistic fuzzy numbers and let IIFWA: $Q^{n} \rightarrow Q$, if

$$
\operatorname{IIFWA} A_{w}\left(\tilde{\alpha}_{1}, \tilde{\alpha}_{2}, \ldots, \tilde{\alpha}_{n}\right)=w_{1} \tilde{\alpha}_{1} \oplus w_{2} \tilde{\alpha}_{2} \oplus \ldots \oplus w_{n} \tilde{\alpha}_{n}(9)
$$

then IIFWA is called an interval-valued intuitionistic fuzzy weighted averaging (IIFWA) operator, where $Q$ is the set of all IVIFNs, $w=\left(w_{1}, w_{2}, \ldots, w_{n}\right)$ is the weight vector of the IVIFNs $\tilde{\alpha}_{j}(j=1,2, \ldots, n)$, and $w_{j}>0, \sum_{j=1}^{n} w_{j}=1$. The IIFWA operator can be further transformed into the following form:

$$
\begin{array}{r}
I I F W A_{w}\left(\tilde{\alpha}_{1}, \tilde{\alpha}_{2}, \ldots, \tilde{\alpha}_{n}\right)=\left(\left[1-\left(\prod_{i=1}^{n}\left(1-a_{i}\right)\right)^{w_{i}}\right.\right. \\
\left.\left.1-\left(\prod_{i=1}^{n}\left(1-b_{i}\right)\right)^{w_{i}}\right],\left[\left(\prod_{i=1}^{n} c_{i}\right)^{w_{i}},\left(\prod_{i=1}^{n} d_{i}\right)^{w_{i}}\right]\right)
\end{array}
$$

Especially if $w=(1 / n, 1 / n, \ldots, 1 / n)$, then the IIFWA operator reduces to an interval-valued intuitionistic fuzzy averaging (IIFA) operator, where

$$
\operatorname{IIFA}\left(\tilde{\alpha}_{1}, \tilde{\alpha}_{2}, \ldots, \tilde{\alpha}_{n}\right)=\frac{1}{n}\left(\tilde{\alpha}_{1} \oplus \tilde{\alpha}_{2} \oplus \ldots \oplus \tilde{\alpha}_{n}\right)
$$

$$
\begin{aligned}
= & \left(\left[1-\left(\prod_{i=1}^{n}\left(1-a_{i}\right)\right)^{1 / n}, 1-\left(\prod_{i=1}^{n}\left(1-b_{i}\right)\right)^{1 / n}\right],\right. \\
& {\left.\left[\left(\prod_{i=1}^{n} c_{i}\right)^{1 / n},\left(\prod_{i=1}^{n} d_{i}\right)^{1 / n}\right]\right) }
\end{aligned}
$$

Definition 2: Let $\tilde{\alpha}_{j}(j=1,2, \ldots, n)$ be a collection of IVIFNs. An IIFHA operator of dimension $n$ is a mapping IIFHA: $Q^{n} \rightarrow Q$ which has associated with it a weighting vector $\omega=\left(\omega_{1}, \omega_{2}, \ldots, \omega_{n}\right)^{\mathrm{T}}$ with the conditions $\omega_{\mathrm{j}}>0$ and $\sum_{\mathrm{j}=1}^{\mathrm{n}} \omega_{\mathrm{j}}=1$, such that

$$
\operatorname{IIFHA}_{\omega, \mathrm{w}}\left(\widetilde{\alpha}_{1}, \widetilde{\alpha}_{2}, \ldots, \widetilde{\alpha}_{\mathrm{n}}\right)=\sum_{\mathrm{j}=1}^{\mathrm{n}} \mathrm{w}_{\mathrm{j}} \overline{\widetilde{\alpha}}_{\sigma(\mathrm{j})}
$$

The weight vector of the ordered weighted aggregation (OWA) operator $\omega=\left(\omega_{1}, \omega_{2}, \ldots, \omega_{n}\right)^{T}$ are obtained by Eq. (13):

$$
\omega_{j}=\frac{e^{-\left[\left(i-\mu_{n}\right)^{2} / 2 \sigma_{n}^{2}\right]}}{\sum_{i=1}^{n} e^{-\left[\left(j-\mu_{n}\right)^{2} / 2 \sigma_{n}^{2}\right]}}, \mathrm{j}=1,2, \ldots, \mathrm{n}
$$

where

$$
\mu_{\mathrm{n}}=\frac{1+\mathrm{n}}{2} \text { and } \sigma_{\mathrm{n}}=\sqrt{\frac{1}{\mathrm{n}} \sum_{\mathrm{i}=1}^{\mathrm{n}}\left(\mathrm{i}-\mu_{\mathrm{n}}\right)^{2}} .
$$

Table 1 gives the weight vector of the ordered weighted aggregation (OWA) operator for various dimensions of matrices.

\begin{tabular}{c|cccc}
\hline Weights & $\mathrm{n}=3$ & $\mathrm{n}=4$ & $\mathrm{n}=5$ & $\mathrm{n}=6$ \\
\hline $\mathrm{w}_{1}$ & 0.243 & 0.155 & 0.112 & 0.086 \\
$\mathrm{w}_{2}$ & 0.514 & 0.345 & 0.236 & 0.172 \\
$\mathrm{w}_{3}$ & 0.243 & 0.345 & 0.304 & 0.242 \\
$\mathrm{w}_{4}$ & - & 0.155 & 0.236 & 0.242 \\
$\mathrm{w}_{5}$ & - & - & 0.112 & 0.172 \\
$\mathrm{w}_{6}$ & - & - & - & 0.086 \\
\hline
\end{tabular}

Table 1: Weighting vectors for various dimensions

Based on the basic operations of IVIFSs, Eq. (12) can be further transformed to Eq. (15)

$\operatorname{IIFHA}_{w, \omega}\left(\tilde{\alpha}_{1}, \tilde{\alpha}_{2}, \ldots, \tilde{\alpha}_{n}\right)=\left(\left[1-\left(\prod_{j=1}^{n}\left(1-\bar{a}_{\sigma(j)}\right)\right)^{\omega_{j}}\right.\right.$,

$\left.\left.1-\left(\prod_{j=1}^{n}\left(1-\bar{b}_{\sigma(j)}\right)\right)^{\omega_{j}}\right],\left[\prod_{i=1}^{n} \bar{c}_{\sigma(j)}^{\omega_{j}}, \prod_{i=1}^{n} \bar{d}_{\sigma(j)}^{\omega_{j}}\right]\right)$

Definition 3. Let $\tilde{\alpha}=([a, b],[c, d])$ be an intervalvalued intutionistic fuzzy set. A score function of $S$ for ranking interval valued intuitionistic fuzzy values can be represented as follows:

$$
S(\tilde{\alpha})=\frac{a-b+c-d}{2},
$$

where $S(\tilde{\alpha}) \in[-1,1]$. The greater the value of $S(\tilde{\alpha})$, the greater the IVIFN $\tilde{\alpha}$.

Definition 4: Let $\tilde{\alpha}=([a, b],[c, d])$ be an intervalvalued intutionistic fuzzy set. In this study, the following score function is proposed for defuzzifying $\tilde{\alpha}$ :

$$
I(\widetilde{\alpha})=\frac{a+b+(1-c)+(1-d)+a \times b-\sqrt{(1-c) \times(1-d)}}{4}
$$

In Eq.(17) the terms (1-c) and (1-d) convert nonmembership degrees to membership degrees while the 
term $\sqrt{(1-c) \times(1-d)}$ " decreases the defuzzified value as much as the magnitude of non-membership.

\section{Fuzzy multicriteria method for real estate dis- trict selection}

The used method is adopted from the study of Chen et al. (2011). The proposed method is composed of two stages in which Stage 1 determines the weights of the criteria based on the pairwise comparison matrices while Stage 2 selects the best alternative/s based on the decision matrices. The steps of the multicriteria method are summarized in the following.

\section{Stage 1}

Step 1. Construct the fuzzy preference relation matrix composed of linguistic terms assigned from Table 2 for the pairwise comparisons of criteria by each expert.

\begin{tabular}{l|l}
\hline Linguistic Terms & Membership \& Non-membership \\
\hline Absolutely Low (AL) & $([0.1,0.25],[0.65,0.75])$ \\
Very Low (VL) & $([0.15,0.3],[0.6,0.7])$ \\
Low (L) & $([0.2,0.35],[0.55,0.65])$ \\
Medium Low (ML) & $([0.25,0.4],[0.5,0.6])$ \\
Approximately Equal (AE) & $([0.45,0.55],[0.3,0.45])$ \\
Medium High (MH) & $([0.5,0.6],[0.25,0.4])$ \\
High (H) & $([0.55,0.65],[0.2,0.35])$ \\
Very High (VH) & $([0.6,0.7],[0.15,0.3])$ \\
Absolutely High (AH) & $([0.65,0.75],[0.1,0.25])$ \\
Exactly Equal (EE) & $([0.5,0.5],[0.5,0.5])$ \\
\hline
\end{tabular}

Table 2: Linguistic scale and its corresponding values

Step 2. Convert the interval-valued intuitionistic fuzzy preference relation matrix on criteria for each expert.

$$
\tilde{G}_{k}=\left[\begin{array}{ccc}
\tilde{g}_{11}^{(k)} & \cdots & \tilde{g}_{1 p}^{(k)} \\
\vdots & \ddots & \vdots \\
\tilde{g}_{p 1}^{(k)} & \cdots & \tilde{g}_{p p}^{(k)}
\end{array}\right], \mathrm{k}=1,2, \ldots, \mathrm{m}
$$

Step 3. Apply the operation in Eq. (11) to aggregate each row of preference relations.

Step 4. Apply Eq. (15) to integrate experts' opinions on criteria, and express the criterion weights in the interval-valued intuitionistic fuzzy format as follows:

$$
\tilde{g}_{j}=I I F H A_{\omega, w}\left(\tilde{g}_{j}^{(1)}, \tilde{g}_{j}^{(2)}, \ldots, \tilde{g}_{j}^{(m)}\right)
$$

Eq.(15) transforms to Eq. (20)

$$
\begin{aligned}
& \operatorname{IIFHA}_{w, \omega}\left(\tilde{\alpha}_{1}, \tilde{\alpha}_{2}, \ldots, \tilde{\alpha}_{n}\right)=\left(\left[1-\left(1-\bar{a}_{\sigma(j)}\right)^{m \omega_{j}},(20)\right.\right. \\
& \left.\left.1-\left(1-\bar{b}_{\sigma(j)}\right)^{m \omega_{j}}\right],\left[\bar{c}_{\sigma(j)}^{m \omega_{j}}, \bar{d}_{\sigma(j)}^{m \omega_{j}}\right]\right)
\end{aligned}
$$

Step 5. Using Definition 3, rank the $\tilde{g}_{j}^{(k)}$ values.
Step 6. Calculate each interval-valued intuitionistic fuzzy criterion weight using Eq. (15) and substituting $\omega_{\mathrm{j}}$ values in Eq. (13). The calculated $\omega_{\mathrm{j}}$ values can be readily found in Table (1).

Step 7. Defuzzify $\tilde{g}_{j}=\left(\left[a_{j}, b_{j}\right],\left[c_{j}, d_{j}\right]\right) \mathrm{j}=1,2, \ldots, \mathrm{n}$ by applying the score function $I($.$) given in Eq. (17) and$ normalize the obtained weights to provide the sum equal to 1.0 .

\section{Stage 2}

Step 8. Collect decision matrices from experts, composed of alternatives performances with respect to criteria utilizing Table 2 .

$$
\widetilde{D}_{k}=\left[\begin{array}{ccc}
\tilde{d}_{11}^{(k)} & \cdots & d_{1 p}^{(k)} \\
\vdots & \ddots & \vdots \\
\tilde{d}_{p 1}^{(k)} & \cdots & d_{p p}^{(k)}
\end{array}\right], \quad \mathrm{k}=1,2, \ldots, \mathrm{m}
$$

Step 9. Apply Eq.(22) to integrate experts' opinions on alternatives performances with respect to criteria and establish the aggregated decision matrix.

$$
\begin{aligned}
& \operatorname{IIFHA} A_{w, \omega}\left(\tilde{\alpha}_{1}, \tilde{\alpha}_{2}, \ldots, \tilde{\alpha}_{n}\right)=\left(\left[1-\left(1-\bar{a}_{\sigma(j)}\right)^{s \omega_{j}},\right.\right. \\
& \left.\left.1-\left(1-\bar{b}_{\sigma(j)}\right)^{s \omega_{j}}\right],\left[\bar{c}_{\sigma(j)}^{s \omega_{j}}, \bar{d}_{\sigma(j)}^{s \omega_{j}}\right]\right)
\end{aligned}
$$

where $s$ indicates the number of experts.

Step 10. Using Definition 3, rank the $\tilde{d}_{j}^{(k)}$ Values.

Step 11. To obtain the aggregated decision matrix, calculate interval-valued intuitionistic fuzzy values for each alternative using Eq. (15) and the readily given $\omega_{j}$ values in Table 1.

Step 12. Generate the performance values of each alternative by using the weights of criteria obtained in Step 7.

Step 13. Employing Eq.(17), defuzzify the performance scores of the alternatives and determine the best alternative/s.

\section{Application}

In this section, we first state the prerequisites of the purchaser related to the district selection problem for a real estate investment decision. There are six possible alternatives which are Besiktas, Kadikoy, Bakirkoy, Beykoz, Uskudar, and Sariyer since the purchaser prefers a real estate on the sea shore of Istanbul.

In Figure 1, the hierarchy of the problem is illustrated. In the first layer of the hierarchy, the goal is defined while in the second layer, the criteria are stated. In the last level, the alternatives are given. 
In the following we apply the steps of multicriteria selection method.

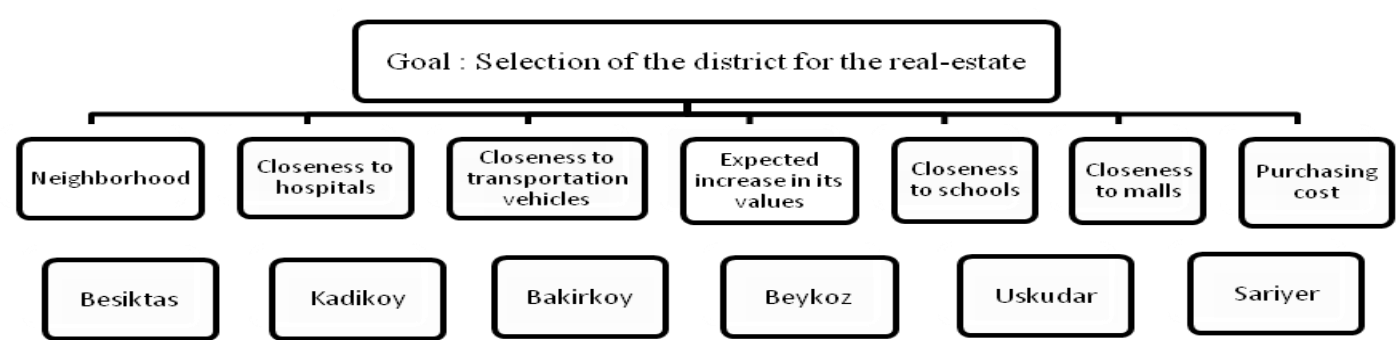

Fig.1: The hierarchical structure of the problem

Step 1. The pairwise comparison matrices for the criteria using intuitionistic fuzzy sets are obtained from three experts as displayed in Tables 3, 4 and 5.

\begin{tabular}{c|ccccccc}
\hline Criteria & $\mathrm{C}_{1}$ & $\mathrm{C}_{2}$ & $\mathrm{C}_{3}$ & $\mathrm{C}_{4}$ & $\mathrm{C}_{5}$ & $\mathrm{C}_{6}$ & $\mathrm{C}_{7}$ \\
\hline $\mathrm{C}_{1}$ & $\mathrm{EE}$ & $\mathrm{ML}$ & $\mathrm{AL}$ & $\mathrm{L}$ & $\mathrm{MH}$ & $\mathrm{H}$ & $\mathrm{VL}$ \\
$\mathrm{C}_{2}$ & & $\mathrm{EE}$ & $\mathrm{L}$ & $\mathrm{ML}$ & $\mathrm{H}$ & $\mathrm{VH}$ & $\mathrm{L}$ \\
$\mathrm{C}_{3}$ & & & $\mathrm{EE}$ & $\mathrm{MH}$ & $\mathrm{AH}$ & $\mathrm{AH}$ & $\mathrm{ML}$ \\
$\mathrm{C}_{4}$ & & & & $\mathrm{EE}$ & $\mathrm{H}$ & $\mathrm{VH}$ & $\mathrm{ML}$ \\
$\mathrm{C}_{5}$ & & & & & $\mathrm{EE}$ & $\mathrm{H}$ & $\mathrm{VL}$ \\
$\mathrm{C}_{6}$ & & & & & & $\mathrm{EE}$ & $\mathrm{AL}$ \\
$\mathrm{C}_{7}$ & & & & & & & $\mathrm{EE}$ \\
\hline
\end{tabular}

Table 3:Linguistic pairwise comparison of the criteria by Expert 1

\begin{tabular}{c|ccccccc}
\hline Criteria & $\mathrm{C}_{1}$ & $\mathrm{C}_{2}$ & $\mathrm{C}_{3}$ & $\mathrm{C}_{4}$ & $\mathrm{C}_{5}$ & $\mathrm{C}_{6}$ & $\mathrm{C}_{7}$ \\
\hline $\mathrm{C}_{1}$ & $\mathrm{EE}$ & $\mathrm{AE}$ & $\mathrm{VL}$ & $\mathrm{L}$ & $\mathrm{MH}$ & $\mathrm{H}$ & $\mathrm{AL}$ \\
$\mathrm{C}_{2}$ & & $\mathrm{EE}$ & $\mathrm{ML}$ & $\mathrm{L}$ & $\mathrm{H}$ & $\mathrm{VH}$ & $\mathrm{VL}$ \\
$\mathrm{C}_{3}$ & & & $\mathrm{EE}$ & $\mathrm{AE}$ & $\mathrm{H}$ & $\mathrm{VH}$ & $\mathrm{AE}$ \\
$\mathrm{C}_{4}$ & & & & $\mathrm{EE}$ & $\mathrm{VH}$ & $\mathrm{AH}$ & $\mathrm{L}$ \\
$\mathrm{C}_{5}$ & & & & & $\mathrm{EE}$ & $\mathrm{MH}$ & $\mathrm{VL}$ \\
$\mathrm{C}_{6}$ & & & & & & $\mathrm{EE}$ & $\mathrm{AL}$ \\
$\mathrm{C}_{7}$ & & & & & & & $\mathrm{EE}$ \\
\hline
\end{tabular}

Table 4: Linguistic pairwise comparison of the criteria by Expert 2

\begin{tabular}{c|ccccccc}
\hline Criteria & $\mathrm{C}_{1}$ & $\mathrm{C}_{2}$ & $\mathrm{C}_{3}$ & $\mathrm{C}_{4}$ & $\mathrm{C}_{5}$ & $\mathrm{C}_{6}$ & $\mathrm{C}_{7}$ \\
\hline $\mathrm{C}_{1}$ & $\mathrm{EE}$ & $\mathrm{ML}$ & $\mathrm{VL}$ & $\mathrm{L}$ & $\mathrm{MH}$ & $\mathrm{H}$ & $\mathrm{VL}$ \\
$\mathrm{C}_{2}$ & & $\mathrm{EE}$ & $\mathrm{L}$ & $\mathrm{ML}$ & $\mathrm{H}$ & $\mathrm{VH}$ & $\mathrm{L}$ \\
$\mathrm{C}_{3}$ & & & $\mathrm{EE}$ & $\mathrm{MH}$ & $\mathrm{AH}$ & $\mathrm{AH}$ & $\mathrm{AE}$ \\
$\mathrm{C}_{4}$ & & & & $\mathrm{EE}$ & $\mathrm{VH}$ & $\mathrm{AH}$ & $\mathrm{ML}$ \\
$\mathrm{C}_{5}$ & & & & & $\mathrm{EE}$ & $\mathrm{MH}$ & $\mathrm{L}$ \\
$\mathrm{C}_{6}$ & & & & & & $\mathrm{EE}$ & $\mathrm{VL}$ \\
$\mathrm{C}_{7}$ & & & & & & & $\mathrm{EE}$ \\
\hline
\end{tabular}

Table 5: Linguistic pairwise comparison of the criteria by Expert 3

Table 6 presents the aggregation results for the experts pairwise comparisons by using Eq. (11). In this table $c_{i j}$ indicates $i$ th expert's opinion for criterion $j$ based on each individual row in the pairwise comparison matrices.

\begin{tabular}{ll}
\hline c11 & $([0.3452,0.4547],[0.4862,0.5871])$ \\
c12 & $([0.4218,0.5267],[0.4069,0.5110]$ \\
c13 & $([0.5521,0.6490],[0.2939,0.3661])$ \\
c14 & $([0.4723,0.5717],[0.3463,0.4555])$ \\
c15 & $([0.2997,0.4156],[0.5224,0.6177])$ \\
c16 & $([0.2128,0.3338],[0.5889,0.6799])$ \\
c17 & $([0.5608,0.6511],[0.2401,0.3621])$ \\
\hline c21 & $([0.3735,0.4767],[0.4609,0.5678])$ \\
c22 & $([0.4088,0.5135],[0.4225,0.5275])$ \\
c23 & $([0.5251,0.6140],[0.2741,0.3973])$ \\
c24 & $([0.5158,0.6112],[0.3065,0.4228])$ \\
c25 & $([0.2948,0.4101],[0.5176,0.6120])$ \\
c26 & $([0.2201,0.3414],[0.5827,0.6737])$ \\
c27 & $([0.5769,0.6682],[0.2277,0.3495])$ \\
\hline c31 & $([0.3505,0.4601],[0.4763,0.5762])$ \\
c32 & $([0.4218,0.5267],[0.4069,0.5110])$ \\
c33 & $([0.5632,0.6543],[0.2414,0.3637])$ \\
c34 & $([0.4909,0.5918],[0.3352,0.4442])$ \\
c35 & $([0.2891,0.4043],[0.5268,0.6220])$ \\
c36 & $([0.2201,0.3414],[0.5827,0.6737])$ \\
c37 & $([0.5386,0.6277],[0.2601,0.3827])$ \\
\hline
\end{tabular}

Table 6: Aggregation of the pairwise comparisons

In Table 7, the experts' weights are reflected to the calculations in Table 6 . Table 8 presents the final weights of the criteria and their defuzzified and normalized values by using Eq. (17). Tables 9-11 illustrate the decision matrices for three experts. The aggregated decision matrix is obtained as listed in Table 12 while in Table 13 , the fuzzy intuitionistic performance scores of alternatives are calculated and the fuzzy scores are defuzzified and normalized as in the right column of the table. The results indicate that the best district for purchasing a real estate is Bakirkoy and it is closely followed by Kadikoy and Besiktas, respectively. In addition, the worst alternative is found as Beykoz. 
c11 ([0.3589,0.4710],[0.4690,0.5716])

c12 ([0.4374,0.5440],[0.3890,0.4941])

c13 ([0.5697,0.6669],[0.2765,0.3482])

c14 ([0.4889,0.5894],[0.3284,0.4379])

c15 ([0.3120,0.4310],[0.5057,0.6030])

c16 ([0.2222,0.3472],[0.5735,0.6669])

c17 $([0.5785,0.6689],[0.2236,0.3441])$

c21 ([0.3880,0.4934],[0.4434,0.5520])

c22 ([0.4241,0.5307],[0.4047,0.5109])

c23 ([0.5425,0.6320],[0.2569,0.3793])

c24 ([0.5331,0.6291],[0.2889,0.4050])

c25 ([0.3070,0.4255],[0.5009,0.5972])

c26 ([0.2297,0.3550],[0.5671,0.6605])

c27 $([0.5948,0.6860],[0.2115,0.3316])$

c31 ([0.3643,0.4765],[0.4590,0.5605])

c32 ([0.4374,0.5440],[0.3890,0.4941])

c33 ([0.5810,0.6721],[0.2248,0.3458])

c34 ([0.5078,0.6096],[0.3174,0.4266])

c35 ([0.3011,0.4195],[0.5101,0.6074])

c36 ([0.2297,0.3550],[0.5671,0.6605])

c37 ([0.5561,0.6456],[0.2432,0.3647])

Table 7. Reflection of experts weights

\begin{tabular}{cc}
\hline $\begin{array}{c}\text { The weights } \\
\text { of criteria }\end{array}$ & $\begin{array}{c}\text { The normalized } \\
\text { weights }\end{array}$ \\
\hline$w_{C 1}=([0.369,0.479],[0.458,0.561])$ & 0.1229 \\
$w_{C 2}=([0.434,0.541],[0.393,0.498])$ & 0.1430 \\
$w_{C 3}=([0.566,0.660],[0.259,0.355])$ & 0.1857 \\
$w_{C 4}=([0.510,0.610],[0.313,0.424])$ & 0.1671 \\
$w_{C 5}=([0.307,0.425],[0.504,0.601])$ & 0.1063 \\
$w_{C 6}=([0.228,0.353],[0.569,0.662])$ & 0.0849 \\
$w_{C 7}=([0.577,0.668],[0.225,0.346])$ & 0.1900 \\
\hline
\end{tabular}

Table 8: The defuzzified and normalized weights of criteria

\begin{tabular}{c|ccccccc}
\hline \multirow{2}{*}{ Alternatives } & \multicolumn{7}{|c}{ Criteria } \\
\cline { 2 - 8 } & $\mathrm{C}_{1}$ & $\mathrm{C}_{2}$ & $\mathrm{C}_{3}$ & $\mathrm{C}_{4}$ & $\mathrm{C}_{5}$ & $\mathrm{C}_{6}$ & $\mathrm{C}_{7}$ \\
\hline Besiktas & $\mathrm{ML}$ & $\mathrm{VH}$ & $\mathrm{AH}$ & $\mathrm{AH}$ & $\mathrm{VH}$ & $\mathrm{VH}$ & $\mathrm{AL}$ \\
Kadikoy & $\mathrm{VH}$ & $\mathrm{H}$ & $\mathrm{H}$ & $\mathrm{VH}$ & $\mathrm{H}$ & $\mathrm{VH}$ & $\mathrm{VL}$ \\
Bakirkoy & $\mathrm{MH}$ & $\mathrm{H}$ & $\mathrm{AH}$ & $\mathrm{H}$ & $\mathrm{H}$ & $\mathrm{VH}$ & $\mathrm{ML}$ \\
Beykoz & $\mathrm{MH}$ & $\mathrm{AE}$ & $\mathrm{L}$ & $\mathrm{H}$ & $\mathrm{ML}$ & $\mathrm{VL}$ & $\mathrm{ML}$ \\
Uskudar & $\mathrm{VH}$ & $\mathrm{H}$ & $\mathrm{VH}$ & $\mathrm{VH}$ & $\mathrm{MH}$ & $\mathrm{L}$ & $\mathrm{ML}$ \\
Sariyer & $\mathrm{VH}$ & $\mathrm{MH}$ & $\mathrm{L}$ & $\mathrm{H}$ & $\mathrm{MH}$ & $\mathrm{MH}$ & $\mathrm{L}$ \\
\hline
\end{tabular}

Table 9: Decision matrix for Expert 1

\begin{tabular}{c|ccccccc}
\hline \multirow{2}{*}{ Alternatives } & \multicolumn{7}{|c}{ Criteria } \\
\cline { 2 - 8 } & $\mathrm{C}_{1}$ & $\mathrm{C}_{2}$ & $\mathrm{C}_{3}$ & $\mathrm{C}_{4}$ & $\mathrm{C}_{5}$ & $\mathrm{C}_{6}$ & $\mathrm{C}_{7}$ \\
\hline Besiktas & $\mathrm{ML}$ & $\mathrm{VH}$ & $\mathrm{VH}$ & $\mathrm{AH}$ & $\mathrm{AH}$ & $\mathrm{AH}$ & $\mathrm{L}$ \\
Kadikoy & $\mathrm{H}$ & $\mathrm{H}$ & $\mathrm{VH}$ & $\mathrm{AH}$ & $\mathrm{VH}$ & $\mathrm{AH}$ & $\mathrm{VL}$ \\
Bakirkoy & $\mathrm{AE}$ & $\mathrm{VH}$ & $\mathrm{AH}$ & $\mathrm{H}$ & $\mathrm{H}$ & $\mathrm{VH}$ & $\mathrm{ML}$ \\
Beykoz & $\mathrm{H}$ & $\mathrm{AE}$ & $\mathrm{L}$ & $\mathrm{H}$ & $\mathrm{ML}$ & $\mathrm{L}$ & $\mathrm{L}$ \\
Uskudar & $\mathrm{VH}$ & $\mathrm{H}$ & $\mathrm{H}$ & $\mathrm{VH}$ & $\mathrm{H}$ & $\mathrm{AE}$ & $\mathrm{L}$ \\
Sariyer & $\mathrm{H}$ & $\mathrm{H}$ & $\mathrm{L}$ & $\mathrm{AH}$ & $\mathrm{MH}$ & $\mathrm{H}$ & $\mathrm{VL}$ \\
\hline
\end{tabular}

Table 10: Decision matrix for Expert 2

\begin{tabular}{c|ccccccc}
\hline \multirow{2}{*}{ Alternatives } & \multicolumn{7}{|c}{ Criteria } \\
\cline { 2 - 8 } & $\mathrm{C}_{1}$ & $\mathrm{C}_{2}$ & $\mathrm{C}_{3}$ & $\mathrm{C}_{4}$ & $\mathrm{C}_{5}$ & $\mathrm{C}_{6}$ & $\mathrm{C}_{7}$ \\
\hline Besiktas & $\mathrm{L}$ & $\mathrm{VH}$ & $\mathrm{AH}$ & $\mathrm{AH}$ & $\mathrm{VH}$ & $\mathrm{AH}$ & $\mathrm{VL}$ \\
Kadikoy & $\mathrm{MH}$ & $\mathrm{H}$ & $\mathrm{AH}$ & $\mathrm{AH}$ & $\mathrm{VH}$ & $\mathrm{AH}$ & $\mathrm{VL}$ \\
Bakirkoy & $\mathrm{MH}$ & $\mathrm{VH}$ & $\mathrm{VH}$ & $\mathrm{H}$ & $\mathrm{H}$ & $\mathrm{VH}$ & $\mathrm{ML}$ \\
Beykoz & $\mathrm{MH}$ & $\mathrm{AE}$ & $\mathrm{VL}$ & $\mathrm{VH}$ & $\mathrm{AE}$ & $\mathrm{VL}$ & $\mathrm{L}$ \\
Uskudar & $\mathrm{H}$ & $\mathrm{VH}$ & $\mathrm{H}$ & $\mathrm{H}$ & $\mathrm{MH}$ & $\mathrm{L}$ & $\mathrm{ML}$ \\
Sariyer & $\mathrm{H}$ & $\mathrm{MH}$ & $\mathrm{ML}$ & $\mathrm{VH}$ & $\mathrm{AE}$ & $\mathrm{H}$ & $\mathrm{AL}$ \\
\hline
\end{tabular}

Table 11. Decision matrix for expert 3

\begin{tabular}{c|c|c}
\hline weights & $\mathbf{0 . 1 2 2 9}$ & $\mathbf{0 . 1 4 3 0}$ \\
\hline alternatives & $\boldsymbol{C}_{\boldsymbol{I}}$ & $\boldsymbol{C}_{\mathbf{2}}$ \\
\hline Besiktas & $([0.2484,0.4031],[0.4958,0.5980])$ & $([0.6179,0.7175],[0.1364,0.2825])$ \\
Kadikoy & $([0.5690,0.6696],[0.1854,0.3331])$ & $([0.5676,0.6679],[0.1845,0.3321])$ \\
Bakirkoy & $([0.5051,0.6063],[0.2455,0.3947])$ & $([0.6063,0.7062],[0.1484,0.2949])$ \\
Beykoz & $([0.5298,0.6307],[0.2217,0.3703])$ & $([0.4662,0.5676],[0.2825,0.4324])$ \\
Uskudar & $([0.6063,0.7062],[0.1484,0.2949])$ & $([0.5804,0.6807],[0.1731,0.3204])$ \\
Sariyer & $([0.5804,0.6807],[0.1731,0.3204])$ & $([0.5298,0.6307],[0.2217,0.3703])$ \\
\hline weights & $\mathbf{0 . 1 8 5 7}$ & $\mathbf{0 . 1 6 7 1}$ \\
\hline alternatives & $\boldsymbol{C}_{\mathbf{3}}$ & $\boldsymbol{C}_{\mathbf{4}}$ \\
\hline Besiktas & $([0.6564,0.7556],[0.1009,0.2455])$ & $([0.6679,0.7667],[0.0891,0.2333])$ \\
Kadikoy & $([0.6336,0.7337],[0.1247,0.2704])$ & $([0.6063,0.7062],[0.1484,0.2949])$ \\
Bakirkoy & $([0.6564,0.7556],[0.1009,0.2455])$ & $([0.5676,0.6679],[0.1845,0.3321])$ \\
Beykoz & $([0.1965,0.3517],[0.5468,0.6494])$ & $([0.5804,0.6807],[0.1731,0.3204])$ \\
Uskudar & $([0.5804,0.6807],[0.1731,0.3204])$ & $([0.6063,0.7062],[0.1484,0.2949])$ \\
Sariyer & $([0.2218,0.3767],[0.5219,0.6243])$ & $([0.6194,0.7195],[0.1373,0.2834])$ \\
\hline weights & $\mathbf{0 . 1 0 6 3}$ & $\mathbf{0 . 0 8 4 9}$ \\
\hline alternatives & $\boldsymbol{C}_{5}$ & $\boldsymbol{C}_{\boldsymbol{6}}$ \\
\hline Besiktas & $([0.6307,0.7304],[0.1252,0.2708])$ & $([0.6564,0.7556],[0.1009,0.2455])$ \\
Kadikoy & $([0.6063,0.7062],[0.1484,0.2949])$ & $([0.6564,0.7556],[0.1009,0.2455])$ \\
Bakirkoy & $([0.5676,0.6679],[0.1845,0.3321])$ & $([0.6179,0.7175],[0.1364,0.2825])$ \\
Beykoz & $([0.3170,0.4565],[0.4401,0.5521])$ & $([0.1698,0.3253],[0.5730,0.6758])$ \\
Uskudar & $([0.5298,0.6307],[0.2217,0.3703])$ & $([0.2810,0.4208],[0.4823,0.5946])$ \\
Sariyer & $([0.5051,0.6063],[0.2455,0.3947])$ & $([0.5558,0.6564],[0.1967,0.3446])$ \\
\hline
\end{tabular}




\begin{tabular}{cc} 
weights & $\mathbf{0 . 1 9 0 0}$ \\
\hline alternatives & $\boldsymbol{C}_{7}$ \\
\hline Besiktas & $([0.1576,0.3133],[0.5865,0.6898])$ \\
Kadikoy & $([0.1569,0.3124],[0.5849,0.6876])$ \\
Bakirkoy & $([0.2607,0.4151],[0.4830,0.5849])$ \\
Beykoz & $([0.2218,0.3767],[0.5219,0.6243])$ \\
Uskudar & $([0.2484,0.4031],[0.4958,0.5980])$ \\
Sariyer & $([0.1576,0.3133],[0.5865,0.6898])$ \\
\hline
\end{tabular}

Table 12: Aggregated decision matrix

\begin{tabular}{ccc}
\hline Alternatives & Intuitionistic fuzzy scores & $\begin{array}{c}\text { Normalized } \\
\text { scores }\end{array}$ \\
\hline Besiktas & $([0.840,0.919],[0.091,0.162])$ & 0.1744 \\
Kadikoy & $([0.841,0.917],[0.072,0.142])$ & 0.1753 \\
Bakirkoy & $([0.840,0.916],[0.051,0.114])$ & 0.1764 \\
Beykoz & $([0.668,0.805],[0.146,0.247])$ & 0.1442 \\
Uskudar & $([0.813,0.899],[0.069,0.141])$ & 0.1709 \\
Sariyer & $([0.753,0.861],[0.118,0.208])$ & 0.1587 \\
\hline
\end{tabular}

Table 13: The fuzzy performance scores of alternatives

The ranking of the alternative are : Bakirkoy $>$ Kadikoy $>$ Besiktas $>$ Uskudar $>$ Sariyer $>$ Beykoz .

\section{Sensitivity Analysis}

In Figure 2, dark blue, red, green, purple, blue and orange colors represent the alternatives Besiktas,Kadikoy, Bakirkoy, Beykoz, Uskudar and Sariyer, respectively. All graphs almost indicate the same result. For the low levels of criteria weights, Bakirkoy takes always the first order. For the criteria weights between 0.20 and 0.35 , Kadikoy always takes the first order. For the criteria weights larger than 0.35 , Sariyer is the selected alternative.

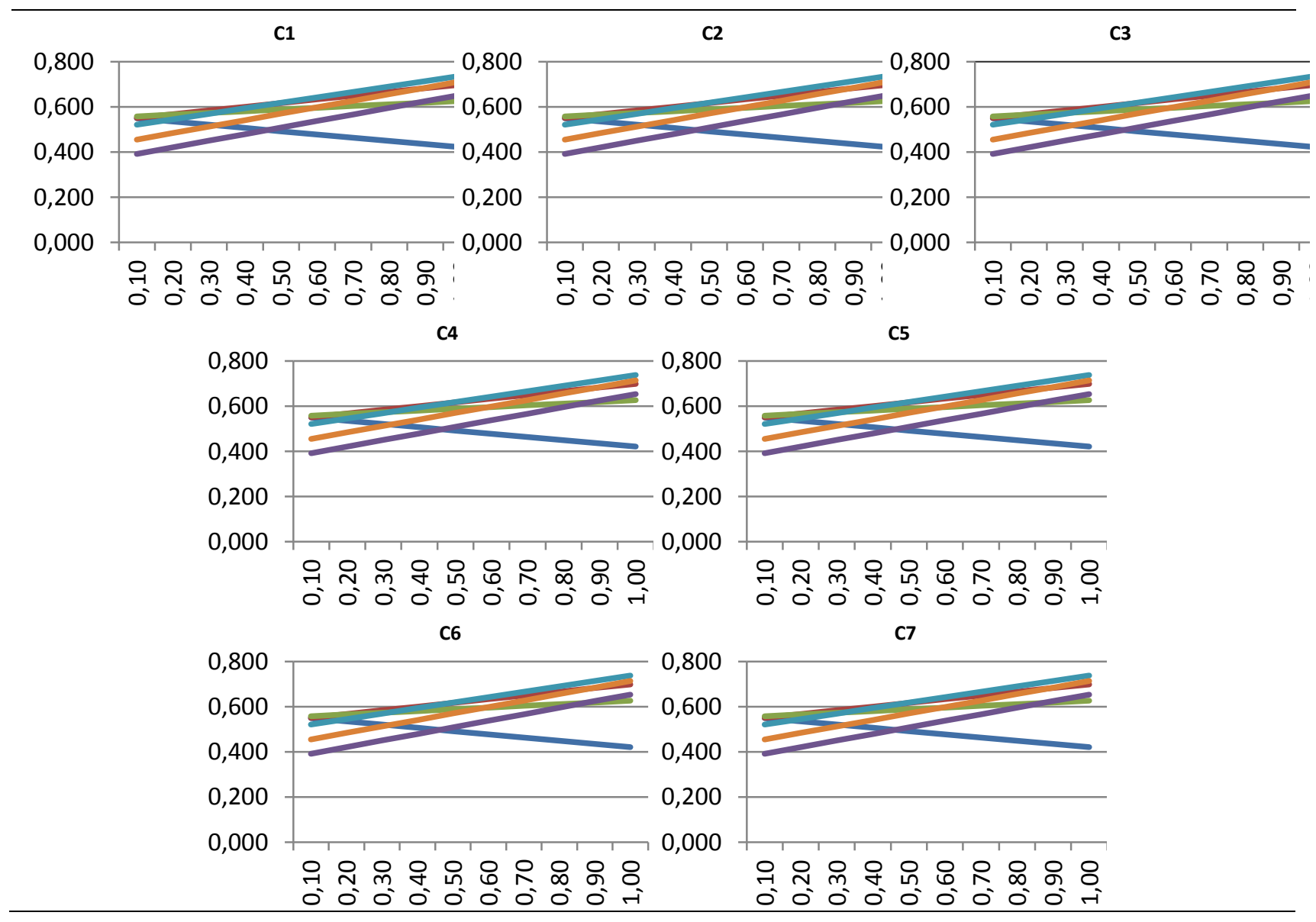

Fig.2: The results of sensitivity analysis 


\section{Conclusions}

Worldwide real estate investment is a multicriteria problem including many conflicting and linguisticvalued attributes. Considering the membership and nonmembership functions as well as hesitancy provides a comprehensive evaluation of criteria and alternatives. Integrating the experts weights to the aggregation process, the importance of past experience have been reflected into the results. Sensitivity analysis is also applied to check if there is a change in the solution when the criteria weights change. Apart from the literature, a new defuzzification method has been proposed in the study.

In this paper, specifically the district selection for real estate investment decision has been realized. For the further researches, we plan to extend the study to select a country and a city before deciding the district in the city. Besides, other fuzzy MCDM methods like TOPSIS, VIKOR, AHP, and ELECTRE with hesitant or intuitionistic fuzzy sets are suggested to apply and compare the results obtained in this study.

\section{References}

[1] B. Roy ,The outranking approach and the

[2] C.L. Hwang and K. Yoon, Multiple Attribute Decision Making: Methods and Applications, SpringerVerlag, New York, 1981.

[3] C.-T. Lin and J.-K. Lin, Fuzzy-GIS approach for applying the ahp multi-criteria decision-making model to evaluate real estate purchases, Journal of Testing and Evaluation, 41(6): 2013.

foundations of ELECTRE methods, Theory and Decision, Kluwer Academic Publishers. Printed in the Netherlands, 31: 49-73, 1991.

[4] J.P. Brans, Lingenierie de la decision. Elaboration dinstruments daide a la decision. Methode PROMETHEE, R. Nadeau, M. Landry (Eds.), Laide a la Decision: Nature, Instrument $\mathrm{s}$ et Perspectives Davenir, Presses de Universite Laval, Qu ebec, Canada, 183-214, 1982.

[5] K. Atanassov and G. Gargov, Interval valued intuitionistic fuzzy sets, Fuzzy Sets and Systems, 31(3): 343-349, Elsevier, 1989.

[6] K.T. Atanassov, Intuitionistic Fuzzy Sets, Fuzzy Sets and Systems, 20: 87-96, Elsevier, 1986.

[7] M.R. Thomas, A weighted multi-attribute site prioritization and selection process for brownfield redevelopment, Environmental Practice, 4(2): 95106, Cambridge Journals, 2002.

[8] R.M. Rodriguez, L. Martinez and F. Herrera, Hesitant Fuzzy Linguistic Term Sets for Decision Making, IEEE Transactions on Fuzzy Systems, 20:109119, IEEE, 2012.

[9] S. Broumi and F. Smarandache, New Operations over Interval Valued Intuitionistic Hesitant Fuzzy Set, Mathematics and Statistics, 2(2): 62-71, 2014.
[10] S. Opricovic, and G.H. Tzeng, Compromise solution by MCDM methods: a comparative analysis of VIKOR and TOPSIS, European Journal of Operational Research, 156(2): 445-455, 2004.

[11]T.L. Saaty, The Analytic Network Process Decision Making with the Analytic Network Process International Series in Operations Research \& Management Science, 95: 1-26, 2006.

[12] T.L. Saaty. Fundamentals of the Analytic Hierarchy Process. RWS Publications, Pittsburgh, 2000.

[13] T.Y. Chen, H.-P. Wang and Y.-Y. Lu, A multicriteria group decision-making approach based on interval-valued intuitionistic fuzzy sets: A comparative perspective, Expert Systems with Applications, 38(6): 7647-7658, Elsevier, 2011.

[14] V. Torra, Hesitant fuzzy sets, International Journal of Intelligent Systems, 25: 529-539, Wiley Periodicals, Inc., 2010.

[15] X.-R. Xue, Study on the application of the supporting system for multi-layer fuzzy decision making in real estate development, Xi'an Jianzhu Keji Daxue Xuebao/Journal of Xi'an University of Architecture and Technology, 37(4): 561-565, 2005.

[16]Z. Xu, A method based on distance measure for interval-valued intuitionistic fuzzy group decision making, Information Sciences, 180(1): 181-190, Elsevier, 2010 